\title{
THE DESIGN PROCESS AT LE CORBUSIER, CASE OF THE RONCHAMP CHAPEL
}

\author{
Outmoune, Nadjat (1,2,3); Arrouf, Abdelmalek (1,2) \\ 1: Laboratory of architectural and urban phenomena modeling and studying (LEMPAU); \\ 2: University of Batna1, Batna, Algeria; 3: University of Biskra
}

\begin{abstract}
This work falls within the empirical studies of design activity. Its project is to understand Le Corbusier's designing way and how does he work and structure his design processes. Doing so, it jumps above the descriptive and doctrinal knowledge of objects produced by "Le Corbusier" to study the actions and mechanisms that led to them.

To achieve its aim, this study uses genetic method, developed by P.M. De Biasi of literary origin, this research method is made of three stages. The first one, which is of empirical nature, is one of data gathering. It leads to the establishment of genesis tables and to the classification of the all collected documents. The second stage, makes the analysis of all the collected documents one by one. It allows the restitution of the creative process of one projects "Le Corbusier" which is "la chapelle de Notre Dame du haut de Ronchamp". The last stage is finally that define the design processe of the this project. The results show that the design activity of "Le Corbuiser" obeys the overall logic of one generic model which may be called his individual designing style.
\end{abstract}

Keywords: Design process, Le Corbusier, Genetic analysis, Case study, Human behaviour in design

\section{Contact:}

Outmoune, Nadjat

University of Batna

Architecture

Algeria

outmoune.nadjat@gmail.com 


\section{INTRODUCTION}

This investigation aims to develop a comprehension of Le Corbusier's way of working, in order to identify his personal design style. To achieve this goal, we worked on the two projects of the Villa Savoy and the chapel of Notre Dame Du Haut de Ronchamp. We have chosen these two famous projects in particular because first, they are very distant in time, and second, are extremely different by their functions and their shapes. The conclusions presented in this paper, are drawn from the study of the two projects. But, because of the lack of space, we present here only the results relating to the analysis of the chapel Ronchamp.

\section{MATERIALS AND METHOD}

To carry out this study, we have first collected the archives of the two projects. These archives are exclusively provided by the Foundation Le Corbusier (FLC) and are distributed into sketches, drafts, hand layer revisions by Le Corbusier and technical drawings made by the draftsmen of his cabinet.

The method used in this research is the genetic approach. It is a recent methodology that has emerged in the literary field. It is a new vision of literary criticism which proposes to study literary texts in their temporal dimension, by focusing on their production mode or their genesis and no more on the final product. For Pierre-Marc De Biasi (2000), a genetic approach to architecture involves the transfer and the adaptation of methods and concepts inherited from the analysis of manuscripts, to objects of investigation that are not specifically textual but rather graphics. Indeed, the genetic approach of architecture or what may be called the architectural genetic criticism is an interpretation of the architectural objects through the study of their designing processes. It consists of an analysis of the different drafts produced, by the designers, during the elaboration of the architectural project, from its birth to the construction site.

In order to achieve a better understanding of the complex and varying logics of the Chapel design process, we begun by creating a genesis file, that we made as exhaustive as possible. In order to build it, we made a general inventory of the collected pieces, we authenticated the doubtful documents and we identified the hands of the different draftsmen. Then, we made the dating of each element of the file and finally we categorized the collected documents by type (program and cartography, drawings and graphic representations, notes, documentation, etc.). At the end of this work, we obtained two subsets of documents that are the texts file and the drawings folder. Each subset of documents has been thoroughly studied. but a priority has been given to the larger subset, which constitutes the heart of the architectural genesis, namely the drawings file. It contains 53 documents in the case of the chapel and 50 documents in the case of La Villa Savoy.

Each document is studied by the mean of three sheets. The first one is a presentation sheet, where we find the document's graphic reproduction and an interpretative synthesis of it. The second one is a grid of genetic analysis used to report the characteristics of the graphic as well as its relationships with the other drawings in the process and with the design space of the project. Finally, the third sheet is dedicated to the discussion of the various points listed in the grid. In some cases, we added a fourth sheet to report the supporting documents. Its role is to reveal the references that served as a source for the studied document (Figure 1).
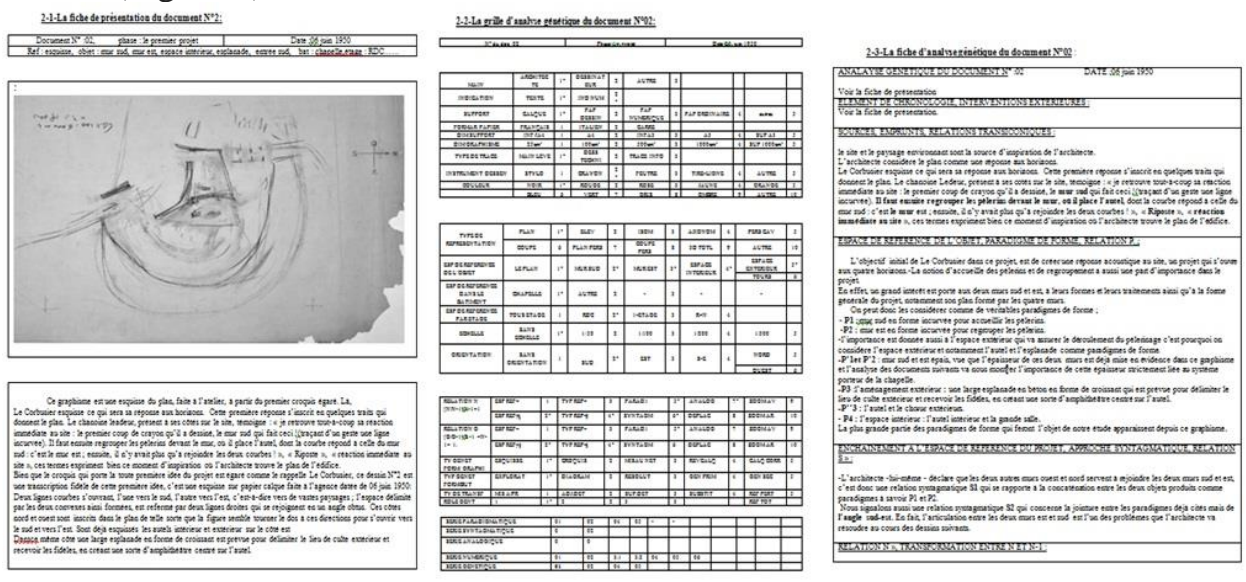

Figure 1: An example of a presentation sheet, an analysis grid and an analysis sheet of a document. 
After applying this approach to all the graphical pieces of the genesis file, we obtained a database that allowed a close and precise reconstruction of the gestures that gave birth to the two projects and that developed their shapes, since the very first sketch of the first idea until the final graphic version.

\section{RESULTS}

\subsection{Study of the genetic objects, form paradigms $(P)$ and syntagmas $(S)$}

The genetic analysis of the Ronchamp and villa Savoy processes, showed that Le Corbusier begins with a very personal interpretation of the project, which he summarizes through a limited number of particular ideas. He divides then his project into a number of virtual entities that can be defined as fragments of the project and on which he focuses his work. The personal ideas and the project fragments are closely related and the former give birth to the latter. Thus, the idea of welcoming pilgrims, for example, produced the fragment Southern wall, and the idea of grouping pilgrims gave the fragments called East wall and Outdoor space.

The so produced entities become subspaces of the architect's design space that he manipulates to produce the project. We call them "genetic objects" or "project parts". Each part or object, is a relatively independent architectural entity but concomitant to all the others. The architect works simultaneously on all of them, with no order of priority or apparent hierarchy. Each genetic object may be linked to others by one or more contiguities or articulations, we call them "Syntagmas". The architect works on them at the same time as the objects.

During the designing activity, the genetic objects go through different conditions. Each one is called "shape paradigm" of the given object. This work identified, for the design of Ronchamp, six genetic objects, fourteen form paradigms and five syntagmas. They are summarized in the Table 1.

Table 1: The objects, paradigms of form and syntagmas of Ronchamp.

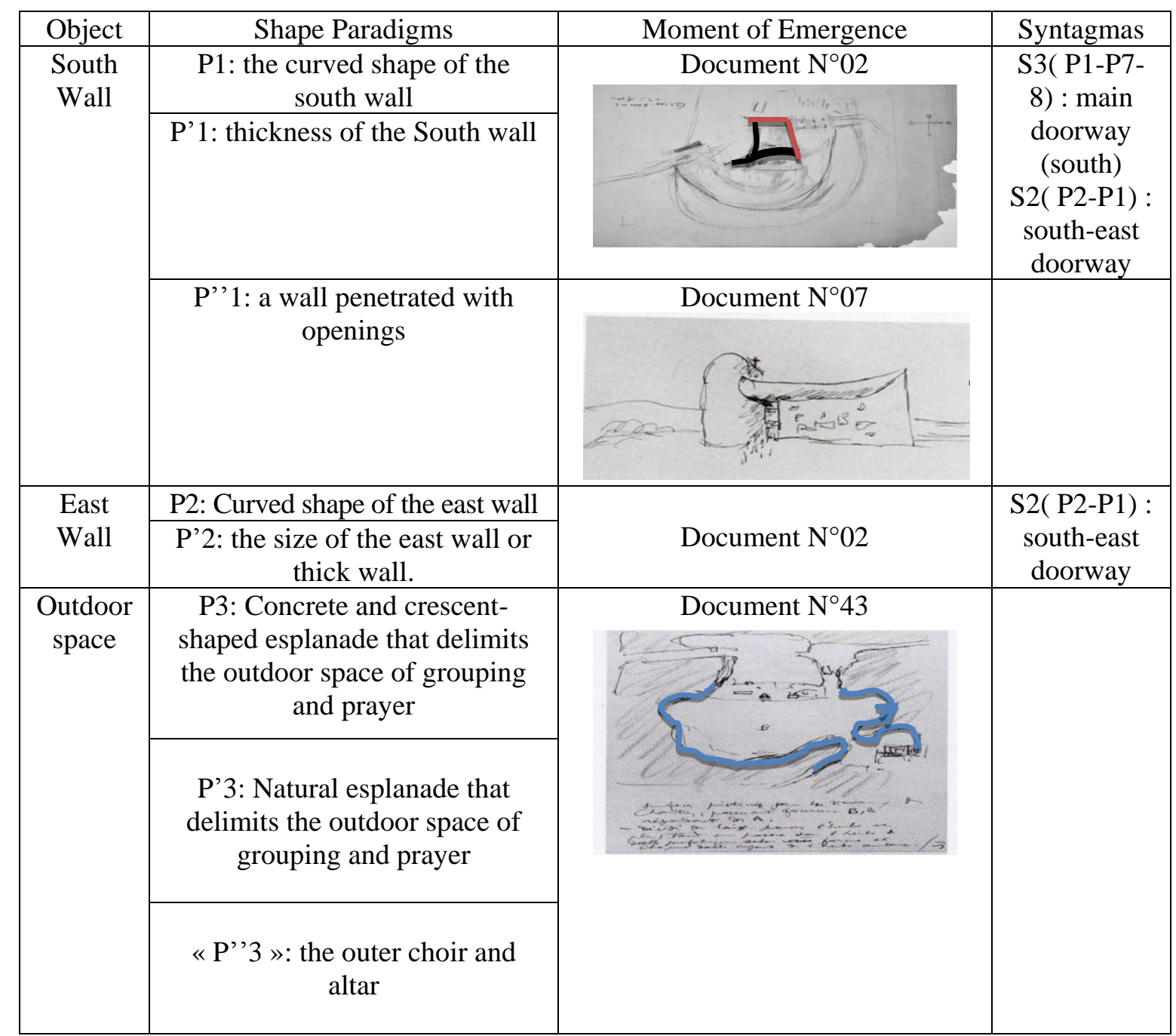




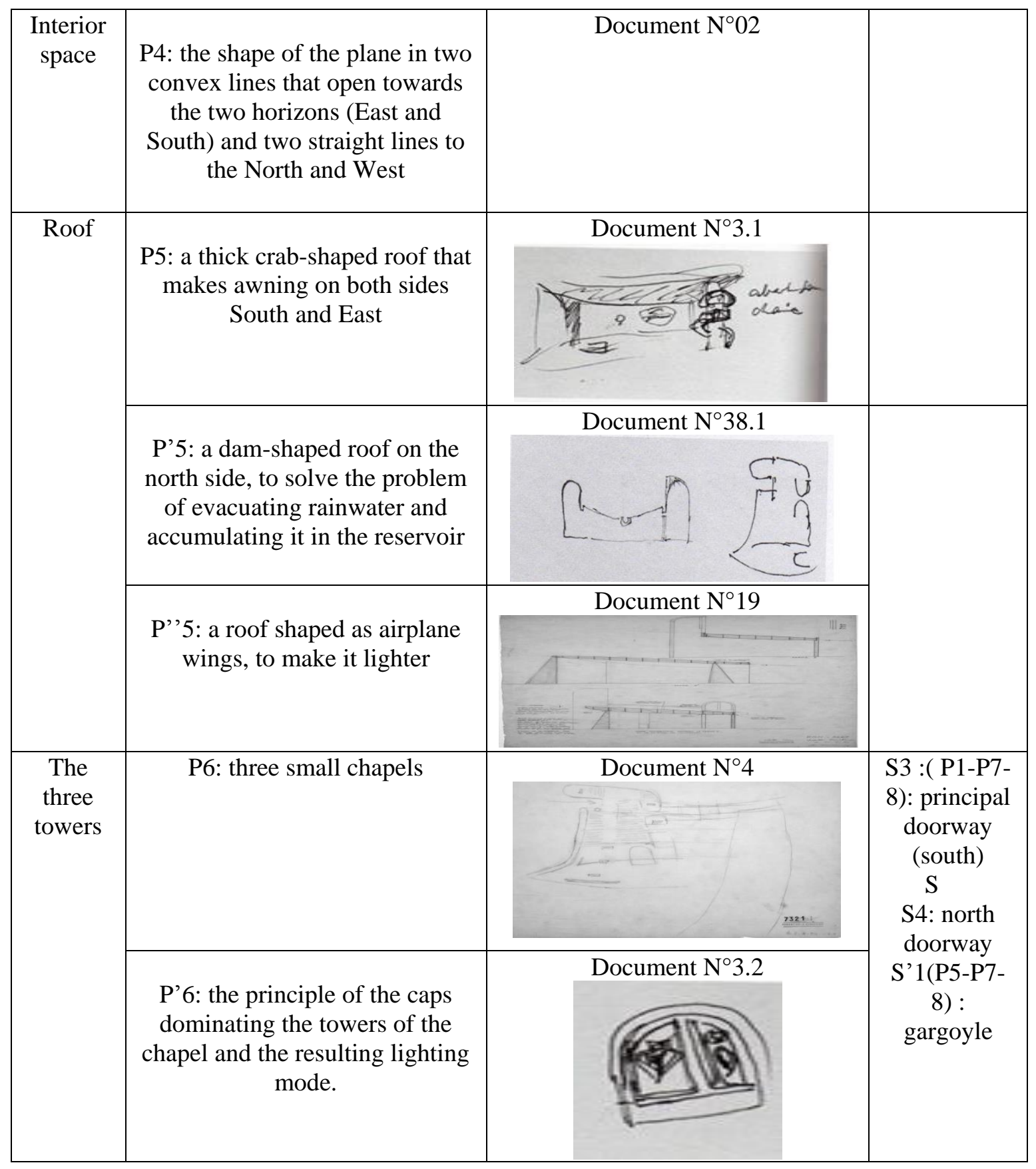

The Table 1 shows that the document number 2 is the core drawing of the process. We find there the concurrent emergence of six shape paradigms out of fourteen, namely: the curved shape of the Southern wall, its thickness, the curved shape of the Eastern wall and its thickness, the shape and function of the outdoor space and finally the overall shape of the plan and the straight shape of the north-west corner. There, Le Corbusier sketches what was his answer to the horizons. This first answer is given in a few lines that give the plan. Half of the syntagmas (2/5) is also born in this document. They are the treatment of the main entrance and the southeast one. The last three syntagmas are also produced at the beginning of the process, in document 3 .

Three others important paradigms, such as the shape of the roof, the three chapels, and the principle of the caps that dominate the towers, appeared early, in documents 3 and 4. This brings the total number of paradigms produced at the very beginning of the process to nine out of fourteen. The important paradigm of the natural lighting principle, through the Southern wall, is also displayed at the beginning of the process and more exactly in the document7. Only two paradigms : the airplane wing shaped roof and the shape of the roof, inspired by the dam form, appeared late in the design process, while remaining paradigms of realization of the paradigm 5, appeared to him in document 3. 
If we consider that the process of Ronchamp counts 53 drawing documents and that after the first seven ones, Le Corbusier defined all the genetic objects and developed the absolute majority of the paradigms of his project, we can conclude that most of the project is produced during the first $13 \%$ of the process time. This is also the case for La Villa Savoy, where all the paradigms and objects were produced during the first eight documents out of the fifty that counts its genesis file.

\subsection{The evolution of the shape paradigms and syntagmas}

The study of the evolution of shape paradigms, during the design process of Ronchamp, shows that, in Le Corbusier's work, the forms produced at the beginning of the process are rarely subject to major changes. Only minimal changes are noted, including additions and deletions of details. They are generally related to the resolution of technical problems and the implementation of the entire project. A good example of that is the curved and thick shape of the South and East walls. It is set in the first sketch and does not vary until the final outcome of the project. This is also the case for the general shape of the plan, which is almost complete within the document number 04 and has not undergone any major transformation since. (Figures 2 and 3 )

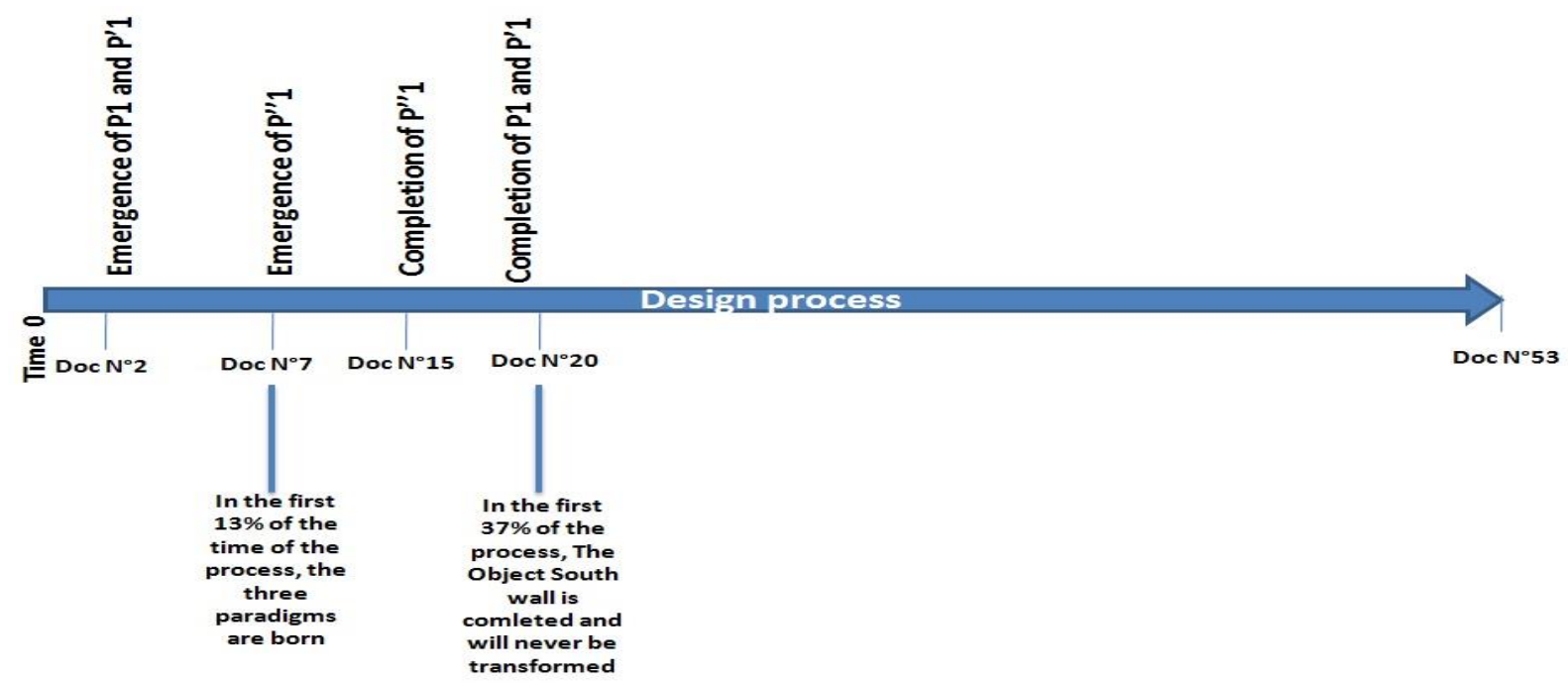

Figure 2: Co-evolution of the shape paradigms of the genetic object "South wall".

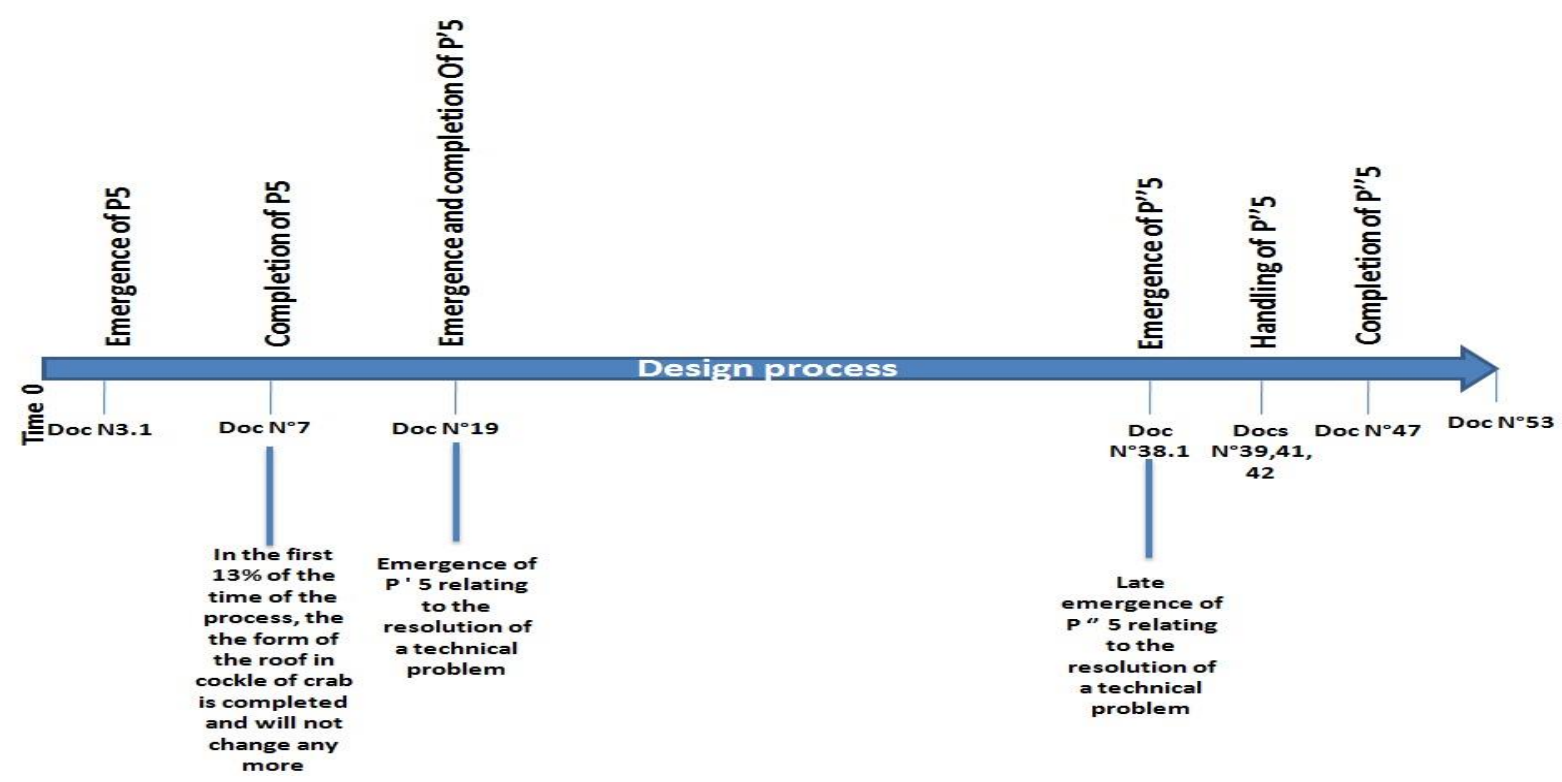

Figure 3: Co-evolution of the shape paradigms of the genetic object "Roof".

The same observation is valid for the evolution of the syntagma. They vary very little during the design process. A good example is the junction between the two walls East and South, which constitutes the syntagma S2.It appears in document 02 where it has a shape of an acute angle. In document04, it is transformed into a second entry, placed at the Southeast of the chapel. In document 
09, the architect returns once more to the plan. This time, the junction is made by stretching the two walls to the Southeast corner and the entrance is placed in the middle of the East wall. But the architect seems to be unsatisfied. He returns once again to the plan in the document 11, where he places the entrance at the corner, on the East wall. The entrance is however scribbled, as if this solution does not convince him too much. But the following documents show that this solution is maintained along the entire design process of the chapel (see Table 2).

Table 2: The evolution of the syntagma S2 during the design process of Ronchamp

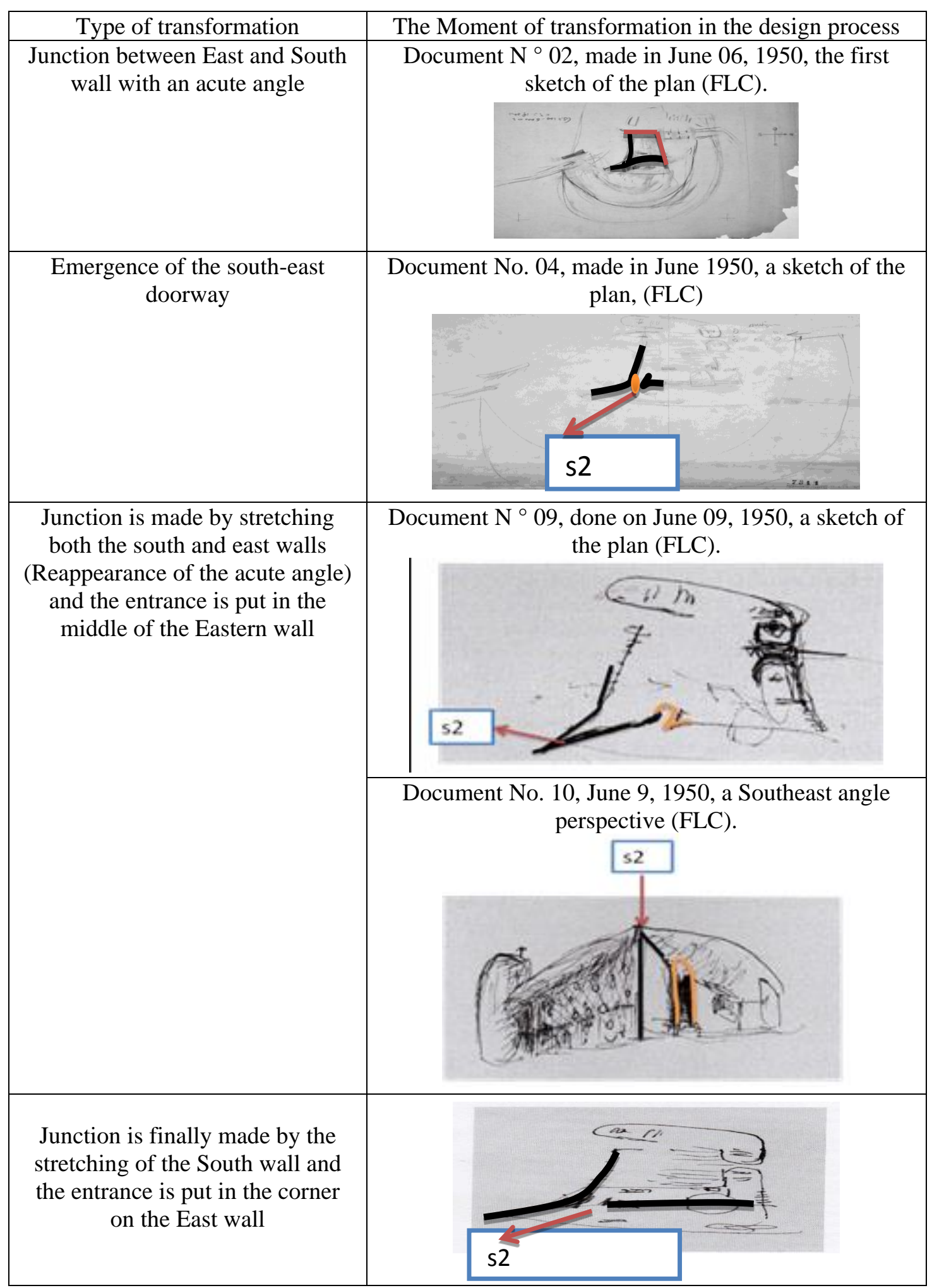




\subsection{The analogical relation " $A$ "}

In addition to the early and concomitant genesis of the genetic objects and paradigms of his project, Le Corbusier uses a form of economy during his designing activity. This is established through the analogical relation "A", provided by the genetic criticism to measure the relationship between different genetic objects and their shape paradigms. It allowed us to understand that Le Corbusier uses, during the design of Ronchamp, operations of duplication, dissemination, concentration and integration.

\subsubsection{The duplication}

During his design, Le Corbusier began by giving the curved shape to the South wall in order to answer the idea of welcoming pilgrims. This shape was then reproduced in the East wall, to ensure the grouping function. He duplicated the same idea of form in two parts of the project, in a kind of economy in the design work that also ensures the homogenization of the project. This strategy adopted by the architect at different moments of his activity is one of the characteristics of his personal designing style.

\subsubsection{The dissemination}

Some issues seem to be of particular concern to Le Corbusier, because once identified; they are disseminated through different moments of the process and contribute greatly to the genesis of the final shape of his project. This is particularly visible in the case of some syntagmas that of the form that may take the intersections of the different walls of the chapel. This issue emerged in the very beginning of the process when Le Corbusier began designing the form that might be taken by the articulation of the South and East walls, and then spread out in the entire project to produce the different entrances of the chapel and the towers which characterize the ends of the walls.

The dissemination strategy allows Le Corbusier to work on a closed set of issues and makes his activity less time-consuming.

\subsubsection{The concentration and integration}

The straight shape given to the corner of the North and West walls in order to integrate the four walls into a single envelope, the combination of three different paradigms: crab shell, airplane wing and dam shape to create the final shape of the roof, the combination of the curved shape, the light streaming obtained through the adopted mode of opening and the huge thickness, in order to produce the final shape of the Southern wall, are all operations of concentration and integration of shape paradigms, carried out by Le Corbusier in order to produce his project.

The operations of concentration and integration give to the shape of the project more homogeneity and more harmony. They make possible and easier the integration of the multiple paradigms manipulated during the process.

\subsection{Sources, quotation, transiconic relations}

The Genetic analysis of Ronchamp revealed that, among its shape paradigms and genetic objects, several are borrowed from sources specific to Le Corbusier. This is, for example, the case of the roof's shape which has been inspired from the shape of a crab shell drawn from the series of organic objects, roots, bones and pebbles that the architect likes to collect and which he calls his "objects of poetic reaction". These are for him valuable sources of inspiration, in his work as an architect as well as a painter and draftsman.

The shape given to the towers and their lighting principle, is another example of borrowing taken this time form Le Corbusier's past travels. He mentions himself this source of inspiration: "light! In 1911, I spotted something like that dug in a Roman cave in Tivoli."This is also the case of the dam form evoked during the design of the roof gargoyle or that of the wings of the aircraft that served as a basis for the design of its construction. These are all sources due to his famous principle, quoted by Pauly (1997): "we draw in order to push inside, in our own history, things seen". 


\section{Discussion}

The genetic analysis of the design processes of Ronchamp and Villa Savoy, revealed that Le Corbusier proceed by a kind of digenetic designing way. During the first sequence, he adopts an arborescent reasoning during which he interprets / divides the project into two sets, one for ideas and the other for objects. The first set derives from the architect personal interpretation and understanding of the project setting and the special meaning she gives to it. This set is at the origin of the second one. That of the genetic objects on which the design work will occur through a series of shape paradigms applied to the different aspects of each object.

Concomitant to this sequence, there is another one during which the architect is concerned with the integration and articulation of the designed objects. He works here on specific syntagma and uses operations of duplication, dissemination, concentration and integration, which allow him to make an economy in the design time and a homogenization of the final form of the project.

Like these two cycles, the genetic objects, the shape paradigms and the syntagma, produced by Le Corbusier, appear all in a very short time and without any apparent order. They emerge at the very beginning of the process, with a level of completion so advanced that they change very little during the design process.

When put together, the virtual objects or entities inform on the main issues addressed by the architect during the design of his project. In the case of Ronchamp, Le Corbusier seems to be interested in four central issues. These are: a) the shape and the configuration of the interior space, which is particularly expressed through the objects South wall and East wall and through the syntagma which deal with their ways of articulation ; b) the shape of the envelope expressed through the objects South wall, East wall and roof and through the syntagma that deal with their articulations ; c) the shape and the constitution of the outer space, which is also expressed through the four objects East and South walls, he shape of the outer space and finally, the shape of the choir.

\section{CONCLUSION}

We will say, by way of conclusion, that the design style of Le Corbusier does exist. The emergence of the project's primary idea is for him synoptic, precocious and fulgurant. It encompasses the essence of the work, which is generally grouped in one drawing, produced from the very beginning of the design process. This early birth is followed by the implementation of the project which allows to develop the primary idea by shaping its parts, by improving them and by solving their technical problems, without completely changing their initial conformation. Ultimately, Le Corbusier's design method leads to a homogeneous, harmonious and integrated product, obtained thanks toa concurrent work on the project different parts and their relations and by mean of operations as duplication, dissemination, concentration and integration, which he practices at different levels of the designing process.

\section{REFERENCES}

Arrouf, A. (2012), Vers une Théorie Scientifique de la Conception Architecturale-Contribution à l'épistémologie Architecturale et à la Modélisation de l'acte de Concevoir, Éditions Universitaires Européennes, Saarinen, Allemagne.

De Biasi, P.M. (2000), “L’horizon Génétique”, in: Louis Hay, Les Manuscrits des Écrivains, Ed. CNRS, Paris, pp. 238-259.

De Biasi, P.-M. (2000), "Pour une approche génétique de l'architecture”, Genesis, No. 14, pp. 7-66.

Le Corbusier (1965), Textes et dessins pour Ronchamp, Frances vives.

Le Corbusier (1996), Le voyage d'Orient, Éditions de la Villette,

Outmoune, N. (2017), "Le processus de conception chez Le Corbusier, variations et permanences", mémoire de magistère, Université de Batna1, Algérie.

Pauly, D. (1997), Le Corbusier- La chapelle de Ronchamp, Fondation Le Corbusier, Birkhäuser, Basel.

\section{ACKNOWLEDGEMENTS}

We thank the Foundation Le Corbusier (FLC) for its precious help, especially the provision of the documents on which we worked on this papers: document $\mathrm{N}^{\circ} 2$, document $\mathrm{N}^{\circ} 7$, document $\mathrm{N}^{\circ} 43$, document $\mathrm{N}^{\circ} 3.1$, document $\mathrm{N}^{\circ} 38.1$, document $\mathrm{N}^{\circ} 19$, document $\mathrm{N}^{\circ} 4$ and document $\mathrm{N}^{\circ} 3.2$. 